Officers and Donald Forsberg, Thomas Nyman, Councillors Franklin Peters, Ronald Rogosheske, Kenneth Schuman, Pat Slingsby, Charles Stanley, Hans Von Mende

Sailors Hans Von Mende, Ronald Rogosheske

Footmen Edmond Poshek, Howard Moody

Production Stage Manager Rex Partington Stage Managers Edward Payson Call, Gordon Smith Assistant to the Director Alfred Rossi

\title{
SCENE EREAKDOWN
}

\begin{tabular}{|c|c|c|c|c|c|}
\hline Page & \multicolumn{2}{|c|}{ Script Scene No. } & \multicolumn{2}{|c|}{ Our Scene No } & Description \\
\hline 1 & Act & 1 , scene & & 1 & Battlements \\
\hline 9 & $"$ & $"$ & ii & 2 & Court \\
\hline 19 & $"$ & $"$ & iii & 3 & Laertes Departure \\
\hline 25 & $"$ & $"$ & iv & 4 & Battlements \\
\hline 29 & $"$ & $"$ & $\mathrm{v}$ & 5 & Hamlet-Ghost \\
\hline 37 & Act & 2 , scene & $\mathrm{i}$ & 6 & Reynaldo-Polonius \\
\hline 42 & $"$ & $"$ & ii & 7 & Court-Arrival Players \\
\hline & & & FIRST IN & NTERMIS & ION \\
\hline 63 & Act & 3 , scene & $\mathrm{i}$ & 8 & Court-Nunnery \\
\hline 70 & $"$ & $"$ & ii & 9 & Advice to Players \\
\hline 74 & $"$ & $"$ & ii (cont'd) & ) 10 & Play scene \\
\hline 85 & $"$ & $"$ & iii & 11 & King's Bedroom \\
\hline 89 & $"$ & $"$ & iv & 12 & Closet \\
\hline 98 & Act & 4, scene & $\mathrm{i}$ & $12 \mathrm{~A}$ & \\
\hline 99 & $"$ & $"$ & ii & 13 & Hide Fox \\
\hline 101 & $"$ & $"$ & iii & 14 & Sending to England \\
\hline 103 & $"$ & $"$ & iv & 15 & Fortinbras \\
\hline & & & SECOND II & [NTERM] & SION \\
\hline 106 & Act & 4, scene & $\mathrm{v}$ & 16 & Court (Mad scene) \\
\hline 115 & " & $"$ & vi & 17 & Court (Letter to Horatio) \\
\hline 116 & $"$ & $"$ & vii & 18 & Court (King-Laertes) \\
\hline 119 & Act & 5 , scene & i & 19 & $\begin{array}{l}\text { Graveyard (Has plotting } \\
\text { from } 18 \text { inserted at end) }\end{array}$ \\
\hline 132 & $"$ & $"$ & ii & 20 & Court (Osric) \\
\hline 140 & $"$ & $"$ & ii (cont'd) & 21 & Court (Finale) \\
\hline
\end{tabular}


